\title{
The nucleotide sequence of the promoter, 16S rRNA and spacer region of the ribosomal RNA operon of Mycobacterium tuberculosis and comparison with Mycobacterium leprae precursor rRNA
}

\author{
Karen E. Kempsell,${ }^{1} \dagger$ Yuan-en Ji ${ }^{1}$ Iris C. E. Estrada-G, ${ }^{2} \ddagger$ M. Joseph Colston ${ }^{2}$ \\ and ROBERT A. CoX ${ }^{1 *}$ \\ ${ }^{1}$ Laboratory of Developmental Biochemistry and ${ }^{2}$ Leprosy and Mycobacterial Research, National Institute for \\ Medical Research, The Ridgeway, Mill Hill, London NW7 1AA, UK
}

(Received 22 August 1991; revised 21 October 1991; accepted 29 October 1991)

\begin{abstract}
Mycobacterium tuberculosis H37Rv has a single rrn (ribosomal RNA) operon. The operon was cloned and a region of 1536 nucleotides was sequenced, starting $621 \mathrm{bp}$ upstream from the $5^{\prime}$-end of the $16 \mathrm{~S}$ rRNA coding region and continuing to the start of the 23S rRNA coding region. The 16S rRNA sequence inferred from the gene sequence was found to differ in one position from Mycobacterium bovis (nucleotide 1443) and from Mycobacterium microti (nucleotide 427). A single putative promoter was identified on the basis of similarities with the sequence of rrn operons of Bacillus subtilis and Escherichia coli. The regions of similarity include a -35 box, a -10 box, a stringent response element, antitermination signals, potential RNAase III processing sites and features of precursor rRNA secondary structure. Sequences upstream from the $5^{\prime}$-end of Mycobacterium leprae 16S rRNA were also investigated. Homologous schemes of secondary structure were deduced for precursor rRNA of both $M$. tuberculosis and $M$. leprae; although the principal features are common to both species there are notable differences.
\end{abstract}

\section{Introduction}

Mycobacteria are of interest because they include important pathogens such as Mycobacterium leprae and Mycobacterium tuberculosis, which have doubling times of $12 \mathrm{~d}$ and $1 \mathrm{~d}$ respectively (Shepard, 1960; Winder \& Rooney, 1970). Several other mycobacteria (e.g. Mycobacterium africanum, Mycobacterium bovis and Mycobacterium microti) are very closely related to $M$. tuberculosis and are classified as members of the $M$. tuberculosis complex (Wayne, 1982). The members of this complex have a single rRNA operon and RFLP analysis has revealed that this operon and its 5'- and $3^{\prime}$-flanking sequences are highly conserved among members of the

* Author for correspondence. Tel. (081) 959 3666; fax (081) 9064477.

† Present address: Department of Surgery, St George's Hospital Medical School, Cranmer Terrace, London SW17 0RE, UK.

¥Present address: Departamento de Immunologia, Escuela Nacional de Ciencias Biologicas, Mexico City, Mexico.

The nucleotide sequence data reported in this paper have been submitted to EMBL and have been assigned the accession numbers $\mathrm{X} 58889, \mathrm{X} 58890$ and X58891. complex (K. E. Kempsell, I. C. E. Estrada-G, M. J. Colston \& R. A. Cox, unpublished work).

This report describes further analysis of the rRNA gene family of $M$. tuberculosis H37Rv. The nucleotide sequence of the promoter region, the $16 \mathrm{~S}$ rRNA coding region, the intercistronic region and the $5^{\prime}$-end of the $23 \mathrm{~S}$ rRNA coding region was established. The promoter region of $M$. tuberculosis, which serves as a model for all members of the $M$. tuberculosis complex, was investigated because of our interest in the control of rRNA synthesis in slow-growing mycobacteria and its role in cell proliferation. The complete $16 \mathrm{~S}$ rRNA sequence allows clarification of the relation of $M$. tuberculosis with other members of the $M$. tuberculosis complex and with other slow-growing mycobacteria.

In addition, we have investigated the nucleotide sequence of the putative leader sequence of the precursor rRNA (pre-rRNA) transcript of $M$. leprae (cf. Sela \& Clark-Curtiss, 1991). The nucleotide sequence of the $M$. leprae rRNA operon was recently published (Liesack et al., 1990, 1991; Sela \& Clark-Curtiss, 1991). Comparisons of the data for $M$. tuberculosis and $M$. leprae reveal interesting similarities and differences. Our results suggest that the single $r r n$ operon of both species 

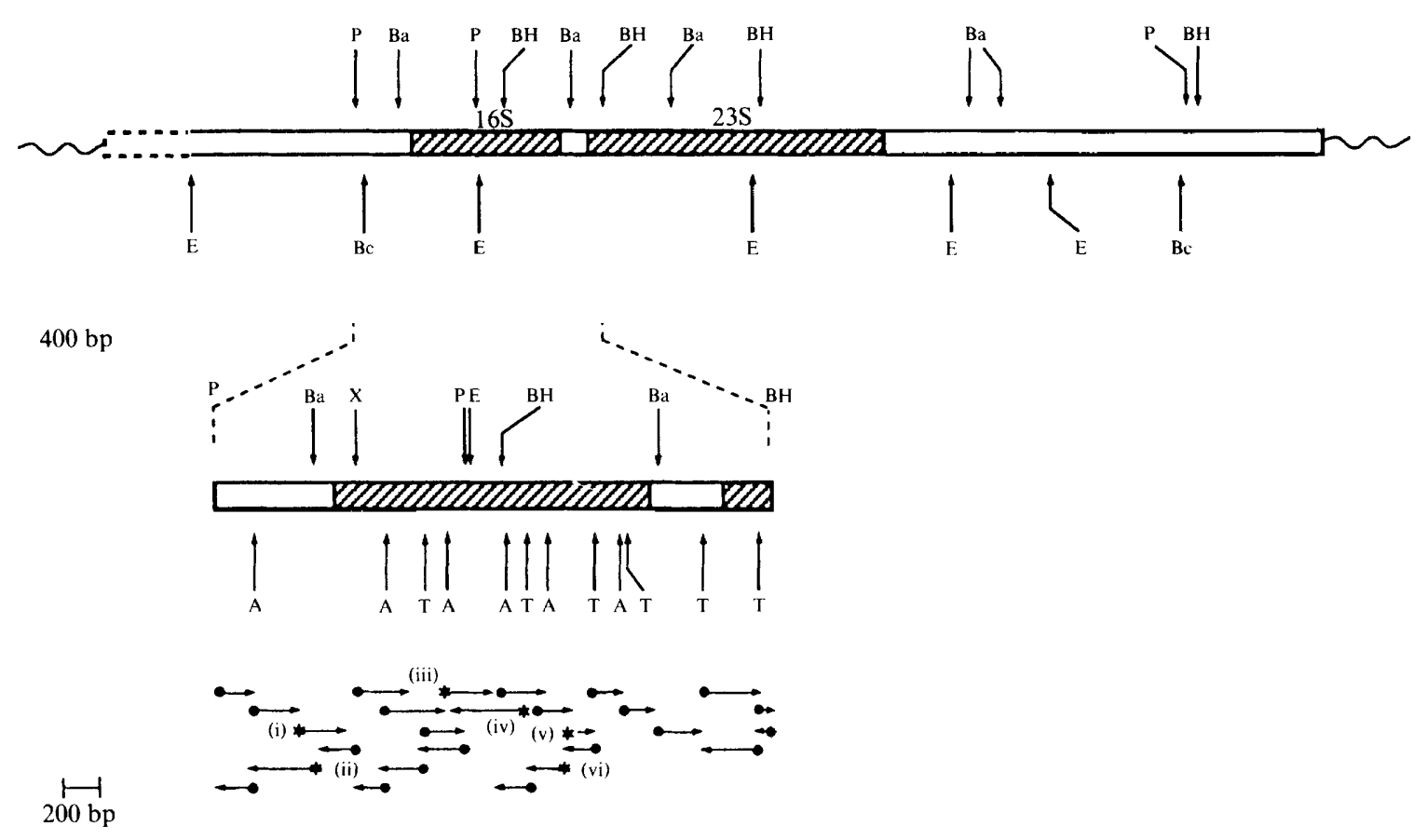

Fig. 1. Restriction site map, sub-cloning and sequencing strategy for the $M$. tuberculosis rRNA cistron. Hatched portions represent $16 \mathrm{~S}$ and 23S rRNA coding regions and unhatched portions denote flanking sequences. Restriction endonucleases used in cloning were: A, AluI ; Ba, BalI; Bc, BclI ; BH, BamHI; E, EcoRI; P, PstI; T, TaqI; X, XhoI. No sites were detected for HindIII or BglII. The regions specified by the arrows with asterisks were sequenced using the oligonucleotide primer indicated using roman numerals (see Table 1). $\sim$, bacteriophage $\lambda$ EMBL3 sequences.

conforms to the general pattern established for a wide range of bacteria (for review see King et al., 1986), in which a single transcript (pre-rRNA) is processed to yield mature $16 \mathrm{~S}$ rRNA and $23 \mathrm{~S}$ rRNA.

\section{Methods}

Materials. All chemicals and enzymes were obtained from suppliers described previously (Cox et al., 1991). T7 sequencing kit was supplied by Pharmacia. DH $5 \alpha \mathrm{F}^{\prime}$ competent cells were supplied by Gibco/BRL. M13/pUC \#1212-sequencing and \#1233-reverse-sequencing primers were obtained from New England Biolabs.

Strain and culture. Strains of Escherichia coli K12 used in library propagation and DNA cloning were LE392 and DH5 $\alpha \mathrm{F}^{\prime}$. Bacterial cells were grown on LB medium (Maniatis et al., 1982) at $37^{\circ} \mathrm{C}$. Bacteriophage $\lambda$ EMBL3 and derivatives were propagated using strain LE392 grown in LB medium plus $10 \mathrm{mM}-\mathrm{MgSO}_{4}$ at $37^{\circ} \mathrm{C}$ for all manipulations. Competent cells of strain $\mathrm{DH} 5 \alpha \mathrm{F}^{\prime}$ were used for transformations with the recombinant plasmids pUC8 and pUC18.

Cloning of the $16 S$ rRNA of $M$. tuberculosis H37Rv. A Sau3A partial library of $M$. tuberculosis H37Rv genomic DNA cloned into the BamHI site of bacteriophage $\lambda$ EMBL3 was provided by Dr E. Davies, Laboratory for Leprosy and Mycobacterial Research, NIMR, London. Bacteriophage plaques were transferred in duplicate onto Hybond- $\mathrm{N}$ nylon membranes according to the manufacturer's instructions. Duplicate filters were then individually hybridized with either probe A [ ${ }^{32} \mathrm{P}$-labelled oligonucleotide g1 (see Table 1)] or with probe B [ ${ }^{32} \mathrm{P}$ labelled oligonucleotide $\mathrm{cg} 6$ (see Table 1)], which recognize respect- ively sequences near to the $5^{\prime}$ - and $3^{\prime}$-ends of a bacterial $16 \mathrm{~S}$ rRNA (Cox et al., 1991). Six recombinants hybridized with both probes. DNA was isolated from each of them using the 'maxi-preparative' method as described in Maniatis et al. (1982). All six clones were found to contain an insert which spanned an identical $11.6 \mathrm{kbp}$ fragment of the rRNA operon characterized by the restriction map shown in Fig. 1. A representative recombinant, bacteriophage $\lambda$ EMBL3-TB1, was selected for sequence analysis.

Cloned $M$. leprae $c D N A$. Clones of the $M$. leprae $\mathrm{rRNA}$ operon were isolated from a cosmid Lawrist 4 library (Cox et al., 1991). The putative leader sequence of precursor rRNA and part of the coding sequence was found in a $901 \mathrm{bp} \mathrm{Sau3A/PstI} \mathrm{fragment,} \mathrm{which} \mathrm{was} \mathrm{sequenced} \mathrm{by}$ standard methods.

Sequencing methods. A $1.2 \mathrm{kbp}$ Pst I fragment containing 5'-16S rRNA gene sequences and upstream sequences was cloned into the Pst I site of plasmid pUC8. A $1 \cdot 1 \mathrm{kbp}$ BamHI fragment containing 3 '-16S rRNA sequences, the spacer region and the 5 -end of 23S rRNA was cloned into plasmid pUC18. Appropriate AluI and TaqI fragments of each of these recombinants were subcloned into pUC18 for sequence determination by the subcloning routine shown in Fig. 1. The $184 \mathrm{bp}$ region located between the $3^{\prime}$-end of the PstI and the $5^{\prime}$-end of the BamHI fragment was synthesized by the PCR reaction using primers $\mathrm{g} 3$ and $\mathrm{cg} 5$ (see Table 1) and the product was isolated using Geneclean. The same product was obtained when either genomic DNA or phage $\lambda$ EMBL3-TB1 DNA was used as substrate. All nucleotide sequences were determined by the dideoxy chain-termination method (Sanger $e t$ al., 1977). PCR amplified fragments were sequenced in triplicate on both strands using a modified Sequenase protocol (Winship, 1989).

Double-strand plasmid template was made single-stranded for sequencing by the $\mathrm{NaOH}$-precipitation method (Murphy \& Ward, 1989). Single strand template was then sequenced in triplicate using 
Table 1. Deoxyribonucleotide primers

(i)-(vi), These primers, identified by roman numerals, were used in sequencing.

A, B, These primers were radiolabelled at the $5^{\prime}$-end with ${ }^{32} \mathrm{P}$ and used to screen the $M$. tuberculosis H37Rv/EMBL3 library.

\begin{tabular}{|c|c|c|}
\hline Primer & Sequence & $\begin{array}{l}\text { Nucleotide position in } \\
M . \text { tuberculosis } 16 \mathrm{~S} \text { rRNA } \\
\text { gene sequence* }\end{array}$ \\
\hline tbpl (i) & 5'(GGTGAGTCTCGGTGCCGAGATCG) 3' & $312-334$ \\
\hline tbp2 (ii) & 5'(GCCAGTCTAATACAAATCCGGCT) $3^{\prime}$ & $405-427$ \\
\hline g3 (iii) & 5'(GTGCCAGCAGCCGCGGTAATACG) $3^{\prime}$ & $1126-1148$ \\
\hline cg5t (iv) & $5^{\prime}\left(\right.$ CGCTTGTGCGGGCCCCCGTCAATT) $3^{\prime}$ & $1531-1554$ \\
\hline v9 (v) & 5'(ACTCGTGAGAGACTGCCGGGGTCÁ)3' & $1758-1781$ \\
\hline v1l (vi) & 5'(GAGTTGACGTCGTCCCCGCCTTCCTC) $3^{\prime}$ & $1787-1813$ \\
\hline gl (A) & $5^{\prime}$ (TTGGAGAGTTTGATCCTGGCTC) 3' & $627-648$ \\
\hline $\operatorname{cg} 6(B)$ & 5'(GGTACGGCTACCTTGTTACGACTT) 3' & $2105-2128$ \\
\hline
\end{tabular}

* See Fig. 2.

$\lceil\mathrm{c}$ indicates that the nucleotide sequence is complementary to the RNA-like strand.

M13/pUC specific \#1212-sequencing and \#1233-sequencing primers and either Sequenase or T7 (Pharmacia) sequencing kits according to the manufacturer's instructions. When necessary, sequence-specific primers (tbpl-vl1) were used (see Table 1 and Fig. 1).

\section{Results}

The recombinant phage $\lambda$ EMBL3-TBI has the same map of restriction endonuclease sites (see Fig. 1) as that established previously for the rRNA operon by analysis of genomic DNA (K. E. Kempsell, I. C. E. Estrada-G, M. J. Colston \& R. A. Cox, unpublished work). The cloning strategy shown in Fig. 1 was used to establish the nucleotide sequence $621 \mathrm{bp}$ upstream from the $5^{\prime}$-end of the 16S rRNA cistron (1536 bp), through the spacer region ( $276 \mathrm{bp}$ ) to the 5 -end of the $23 \mathrm{~S}$ rRNA cistron (the first $105 \mathrm{bp}$ ), as shown in Fig. 2.

\section{M. tuberculosis $16 S \mathrm{rRNA}$ coding region}

The 16S rRNA sequence, inferred from the gene sequence, comprises $1536 \mathrm{bp}$. Previously Rogall et al. (1990) used PCR amplification of a 5'-portion of the $M$. tuberculosis H37Rv 16S rRNA gene to obtain sequence data from the coding region, namely nucleotides 117-261 (nucleotides 738-882, Fig. 2), and nucleotides 429-498 (nucleotides 1040-1119, Fig. 2). Identical sequences were obtained for $M$. bovis, $M$. bovis BCG and M. africanum (Rogall et al., 1990). The partial sequence data of Rogall et al. (1990) and the sequence presented in Fig. 2 are in agreement. Also, sequences near to the 3 '-end (nucleotides 1295-1480) were obtained previously directly from $16 \mathrm{~S}$ rRNA by the use of reverse transcriptase (Estrada-G et al., 1989). Apart from several unidentified nucleotides the sequence determined using reverse transcriptase is very similar to the data shown in Fig. 2. The primary sequence can be folded into a secondary structure which is typical of eubacteria (see Fig. 3).

Comparison of the complete 16S rRNA gene sequence of $M$. tuberculosis with that of M. bovis (Suzuki et al., $1988 a$ ) revealed one difference, the insertion/deletion of a $\mathrm{C}$ residue located in the hairpin loop region of helix 47 [nucleotides 2022-2104, Fig. 2; nucleotides 1401-1483 in the inferred 16S rRNA sequence (Fig. 3)]. The sequence for the hairpin loop is $5^{\prime} \mathrm{CUCG}^{\prime}$ in $M$. tuberculosis (see also Estrada-G et al., 1989) compared with $5^{\prime} \mathrm{CUG}^{\prime}$ for M. bovis, as reported previously (Suzuki et al., 1988a).

The sequence of nucleotides 46-470 of the coding region of 16S rRNA gene of $M$. microti was obtained earlier (EMBL Data Bank accession number X58889; K. E. Kempsell, I. C. E. Estrada-G, M. J. Colston \& R. A. Cox, unpublished work). Compared with $M$. tuberculosis, the $M$. microti sequence is identical except for the deletion of a $T$ residue located at position 427 which leads to the loss of an A-T basepair in helix 17 (Fig. 3).

The anti-Shine-Dalgarno sequence (Shine \& Dalgarno, 1974) comprises a tract of ten pyrimidines located at the $3^{\prime}$-end of $16 \mathrm{~S}$ rRNA (see Figs 2 and 3). At least nine mRNA species of members of the $M$. tuberculosis complex have been sequenced (for review see Dale \& Patki, 1990). The putative Shine-Dalgarno sequence in each of the mRNAs is located six to twelve nucleotides upstream from the AUG or GUG start codon, and has the potential of forming five to eight basepairs with the 3 -end of $16 \mathrm{~S}$ rRNA (see Table 2). $E$. coli has a shorter anti-Shine-Dalgarno sequence (seven nucleotides), and the Shine-Dalgarno sequence is closer (4-7 nucleotides) to the AUG start codon. The functional significance of these differences is not clear. 


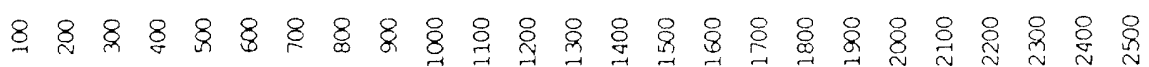

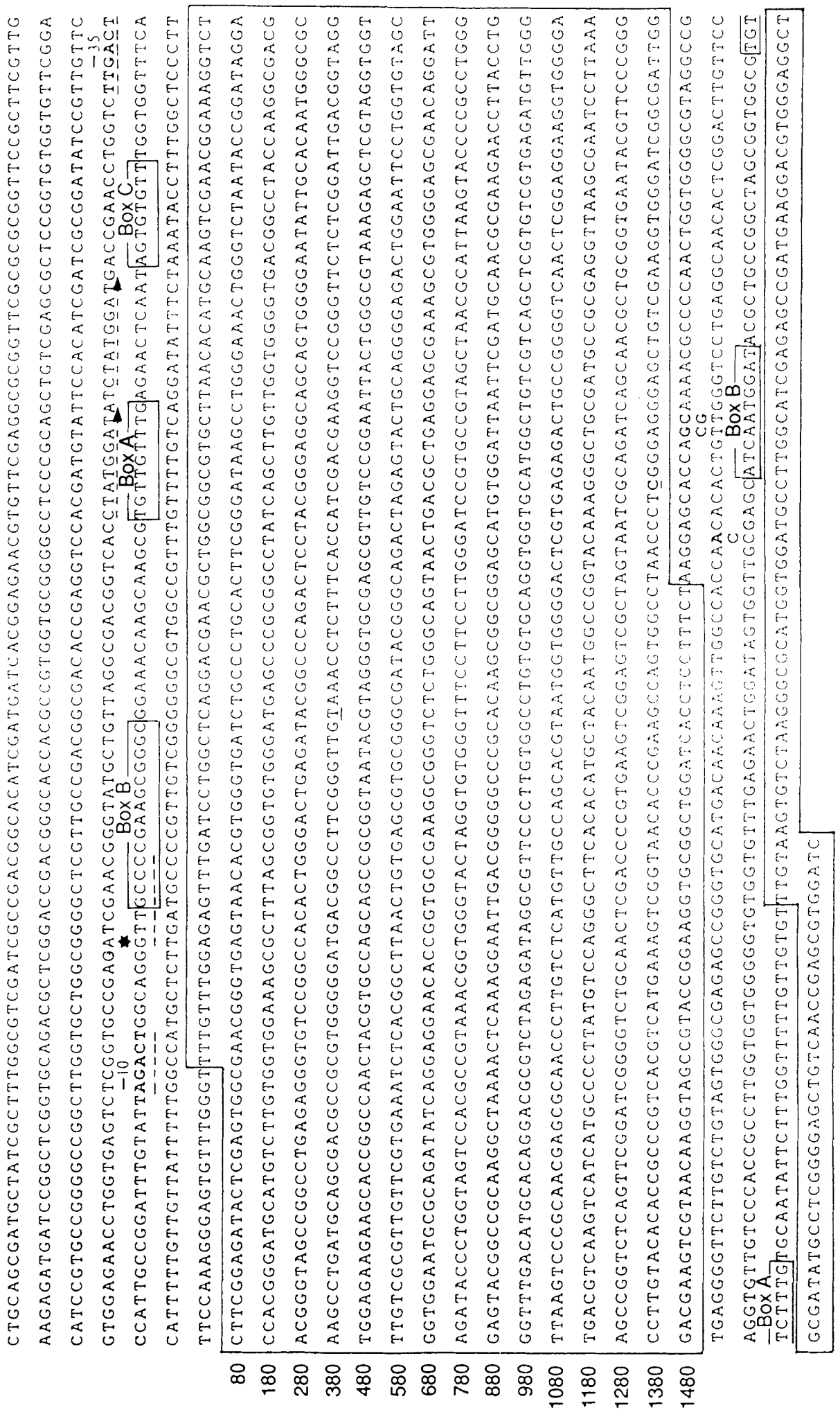

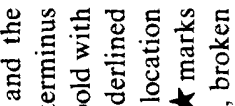

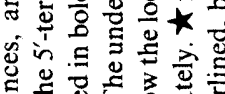

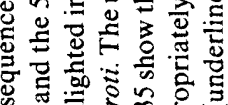

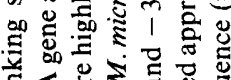

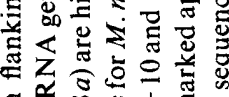

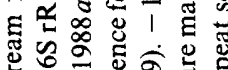

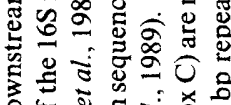

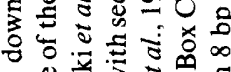
สำ

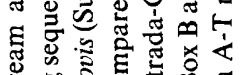

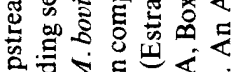

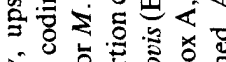

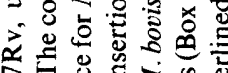

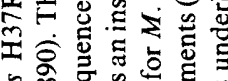

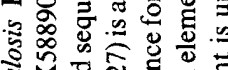

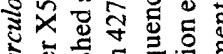

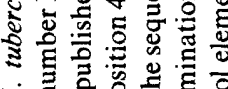

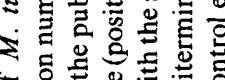
的客

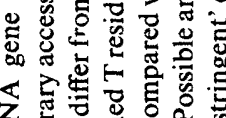

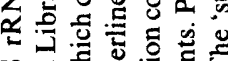

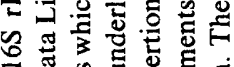

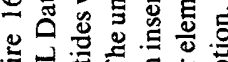

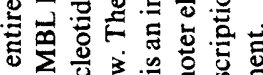

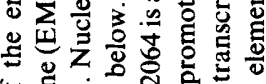

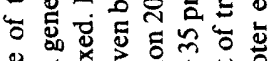

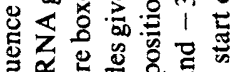

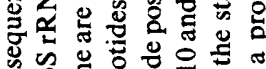

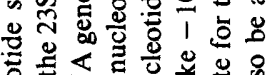

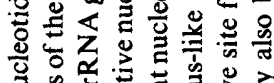

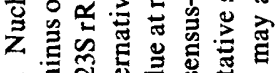

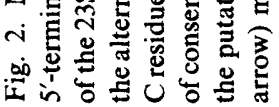



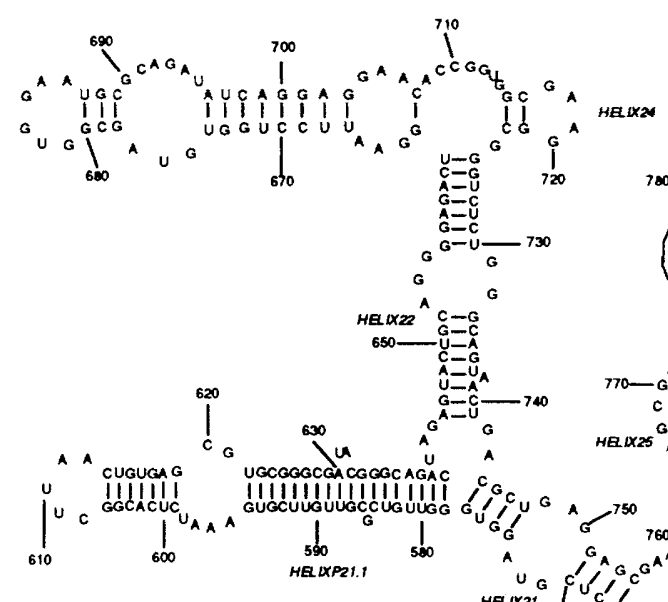

${ }^{780}$

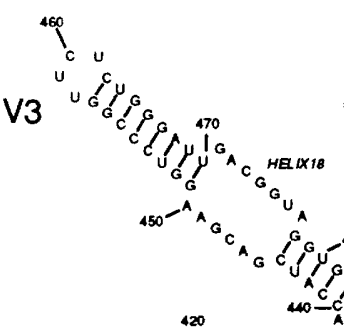

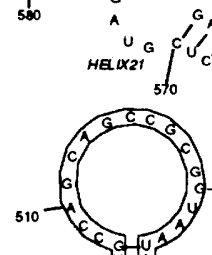

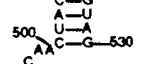

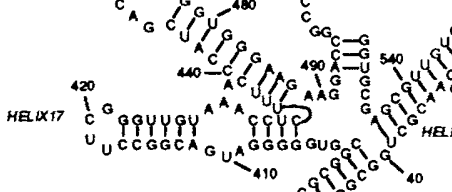

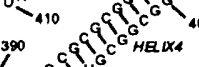

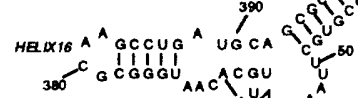
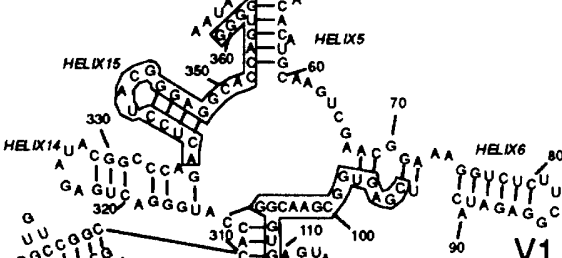

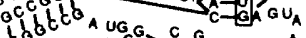

13
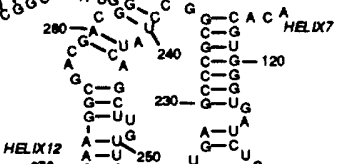

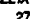

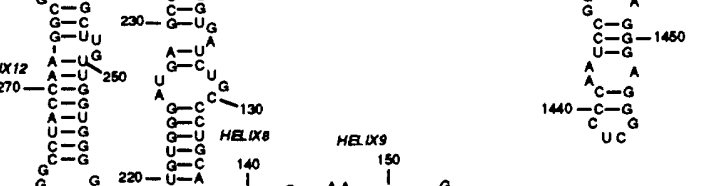

V5

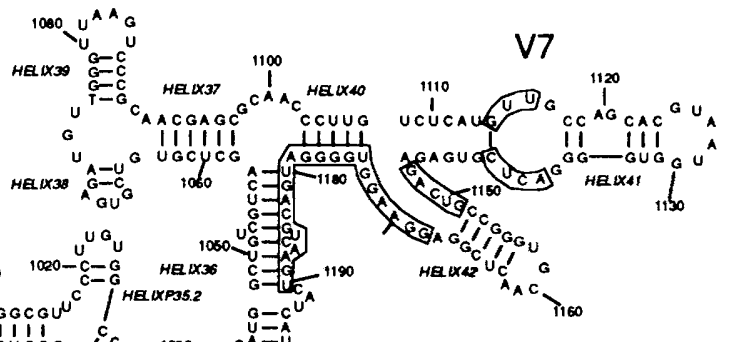

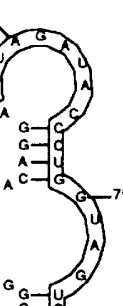<smiles>C1CCC2CCCC2C1</smiles>

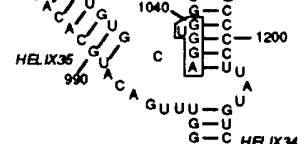<smiles>c1ccccc1</smiles>

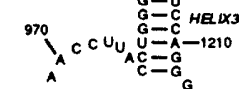

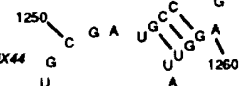

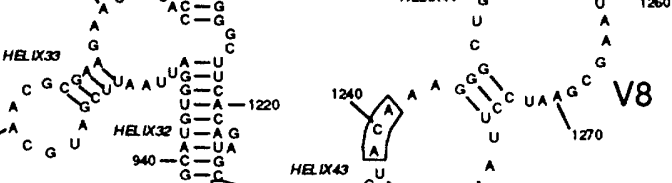

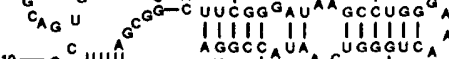

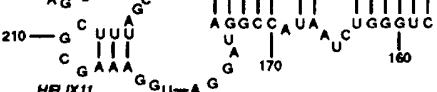

mex $x+1$

V2

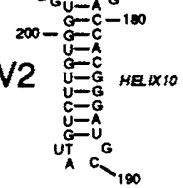

Fig. 3. Schematic secondary structure of $M$. tuberculosis 16S rRNA. The sequence was inferred from the gene (see Fig. 2). The scheme is based on that of Noller (1984) for E. coli and is annotated as described by Dams et al. (1988). The boxed nucleotides are highly conserved among eubacteria. V1, V2 etc. are variable regions. The $M$. bovis sequence (Suzuki et al., 1988a) is identical except for the deletion of a C residue (position 1443) in the hairpin loop region of helix 47. 
Table 2. Shine-Dalgarno and anti-Shine-Dalgarno sequences of the M. tuberculosis complex

Sequences are aligned to maximize $\mathrm{G}-\mathrm{C}$ basepair formation between Shine-Dalgarno and anti-Shine-Dalgarno sequences.

$N_{\mathrm{x}}$ ranges from four to seven nucleotides in $E$. coli mRNA.

Guanine residues participating in 'wobble' (G-U) basepairing are denoted by use of a lowercase letter ' $\mathrm{g}$ '.

\begin{tabular}{|c|c|}
\hline Gene & Sequence \\
\hline \multicolumn{2}{|l|}{ E. coli } \\
\hline $\begin{array}{l}\text { 16S rRNA (anti-Shine-Dalgarno)* } \\
\text { mRNA (hypothetical Shine-Dalgarno) }\end{array}$ & 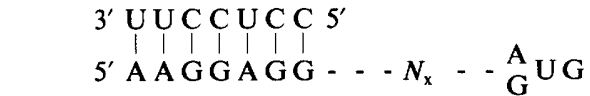 \\
\hline \multicolumn{2}{|l|}{ M. tuberculosis complex } \\
\hline $\begin{array}{l}\text { 16S rRNA (anti-Shine-Dalgarno) } \dagger \\
\text { mRNA (hypothetical Shine-Dalgarno) }\end{array}$ & $\begin{array}{lll}3^{\prime} \text { U C U U U U C C U C C } & 5^{\prime} \\
& \\
5^{\prime} \text { A G A A A G G A G G } & -N_{\mathrm{x}}-{ }_{\mathrm{G}}^{\mathrm{A}} \mathrm{UG}\end{array}$ \\
\hline $\begin{array}{l}\text { M. tuberculosis mRNA (Shine-Dalgarno) }+ \\
\text { dnaJ analogue } \\
10-12 \mathrm{kDa} \text { antigen } \\
19-22 \mathrm{kDa} \text { antigen } \\
32 \mathrm{kDa} \text { antigen } \\
38 \mathrm{kDa} \text { antigen } \\
65 \mathrm{kDa} \text { antigen }\end{array}$ & 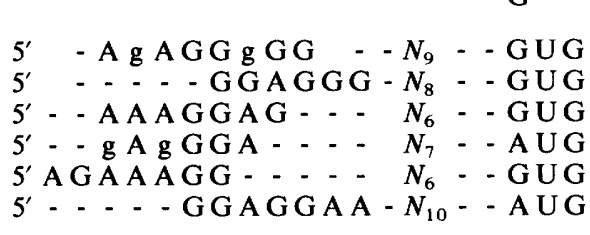 \\
\hline $\begin{array}{l}M . \text { bovis } \mathrm{BCG} \text { mRNA (Shine-Dalgarno) } \ddagger \\
\alpha \text { antigen } \\
18 \mathrm{kDa} \text { antigen } \\
23 \mathrm{kDa} \text { antigen }\end{array}$ & $\begin{array}{l}5^{\prime}-\text { AAAGGgG }--N_{7}-\text { A AG } \\
5^{\prime}-\text { - gAAGAGG }--N_{8}-\text { A A G } \\
5^{\prime}--- \text { - GGAGGAA }-N_{7}-\text { GUG }\end{array}$ \\
\hline
\end{tabular}

* Shine \& Dalgarno (1974)

† See Fig. 3 and Suzuki et al. $(1988 a)$.

‡ For a compilation of mRNA sequences see Dale \& Patki (1990).

Transcription of the M. tuberculosis rrn operon and processing of the transcript

Sequence elements implicated in the control of transcription of the $r r n$ operon and in processing the pre-rRNA transcript to form mature $16 \mathrm{~S}$ and $23 \mathrm{~S}$ rRNA (see Fig. 2) were identified by comparison with elements of known function first established for Bacillus subtilis (Loughney et al., 1983; Ogasawara et al., 1983; Stewart \& Bott, 1983) and E. coli (Young \& Steitz, 1978; Berg et al., 1989; Gourse et al., 1989; Li et al., 1984). These elements have since been recognized in a wide range of bacteria (for review see King et al., 1986).

In total, 11 putative elements were identified, namely -35 box, -10 box, the $5^{\prime}$-end of precursor rRNA (or start of transcription), a stem structure formed between the leader region of the transcript and the intergenic (spacer) sequences separating mature $16 \mathrm{~S}$ rRNA and 23S rRNA, RNAase III processing sites within this stem, and also a second potential processing site in the spacer region, the antitermination signals Box $\mathrm{A}, \mathrm{Box} \mathrm{B}, \mathrm{Box} \mathrm{C}$ in the leader region and Box $A$ and Box $B$ but no Box $C$ in the spacer region, as discussed below.

Consensus sequences established for $r r n$ operons of B. subtilis include the -35 box [5'TTGAC(T/A) $3^{\prime}$ ],
-10 box $\left[5^{\prime} \mathrm{TA}(\mathrm{T} / \mathrm{C})(\mathrm{T} / \mathrm{A})(\mathrm{T} / \mathrm{A}) \mathrm{T} 3^{\prime}\right]$ and the site for the start of transcription (see below). The corresponding sequences for the $r r n$ operon of $M$. tuberculosis (see Fig. 2) are -35 box $\left(5^{\prime}\right.$-TTGACT3') and -10 box (5'TAGACT3').

The start site for transcription of the $r r n$ operon is implicated in the growth-rate regulation and stringent control of transcription. Transcription of tRNA genes is regulated in a similar way (Duester et al., 1982). The 5 -end of transcripts from tRNA and rRNA genes have features which distinguish them from transcription of genes coding for proteins (Ogasawara et al., 1983). The established sequences include 5'GTGGTAG3' for $E$. coli tRNA $^{\text {leu }}$ (Duester et al., 1982); 5'GCCGGCG3' for the E. coli rrnG operon (Li et al., 1984); 5'GTTGTTA3' for $B$. subtilis tRNA (Ogasawara et al., 1983); and $5^{\prime} \mathrm{G}(\mathrm{T} / \mathrm{C})(\mathrm{T} / \mathrm{C}) \mathrm{G}(\mathrm{C} / \mathrm{T}) \mathrm{TT} 3^{\prime}$ for $B$. subtilis rrn operons (Ogasawara et al., 1983). The corresponding sequence for M. tuberculosis (see Fig. 2) is $5^{\prime}$ GTTGCCC3', which conforms to the general pattern.

Antitermination signals which influence the response of RNA polymerase to pause sites and terminator sites have been found in both the leader and spacer regions of the rrn operons of E. coli (Berg et al., 1989; Gourse et al., 1989; Li et al., 1984). The E. coli rrn antitermination 
Fig. 4(a)

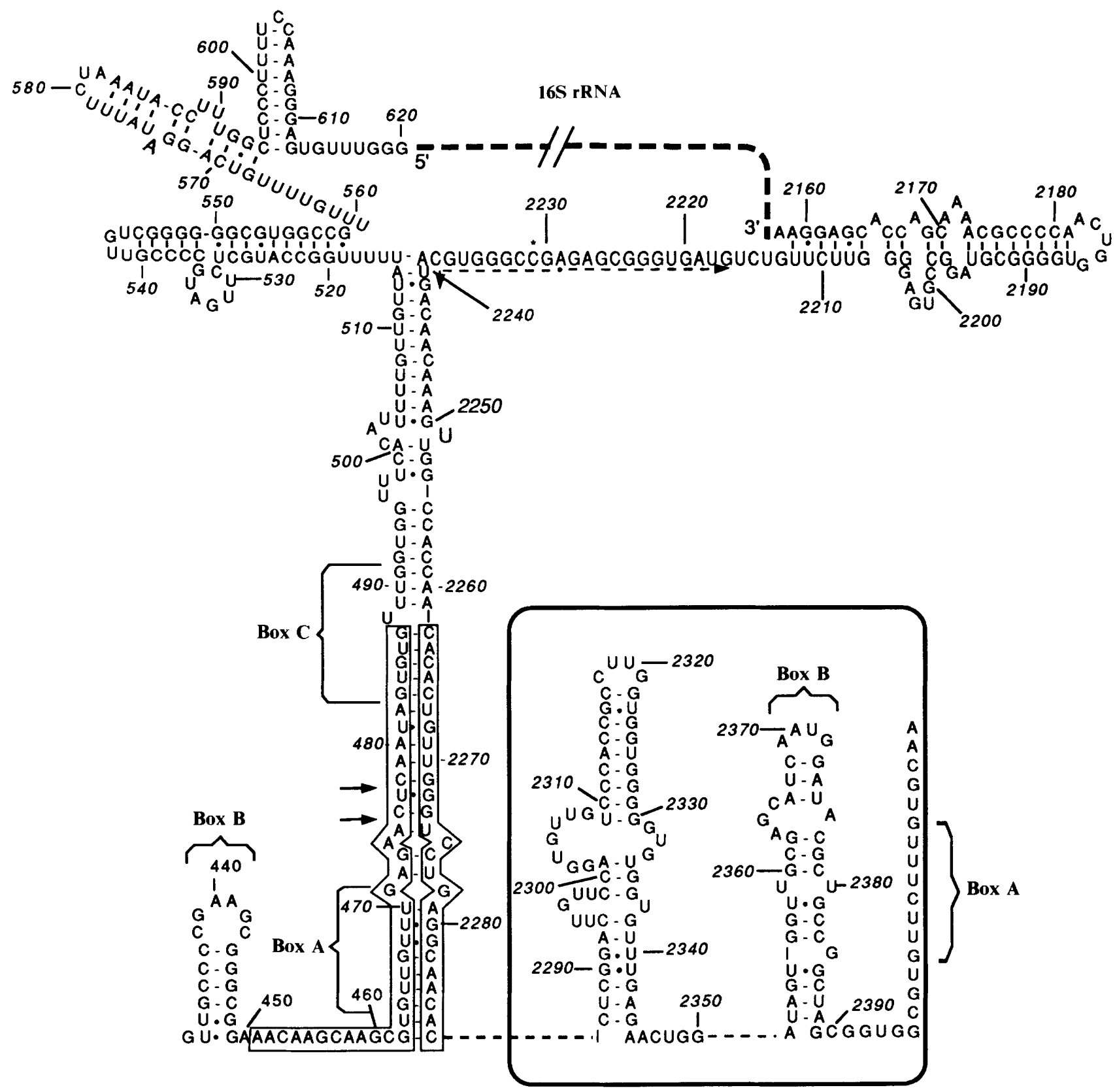

motif appears to be widespread (Berg et al., 1989; King et al., 1986). The elements Box A, Box B and Box C, which were first identified in bacteriophage $\lambda$, were subsequently found in $r r n$ operons of $E$. coli, but in the order Box B, Box A and Box C in the leader region and Box B and Box A (but no Box C) in the spacer region (see, for example, Berg et al., 1989). The three motifs (Box B, Box $A$ and Box C) are found within approximately $70 \mathrm{bp}$ immediately following the E. coli rrnG $\mathrm{P} 2$ promoter (Li $e t$ $a l ., 1984)$. These motifs have their homologues within
65 bp downstream from the putative start of transcription of the rrn operon of $M$. tuberculosis (see Fig. 2).

Box $B$ is a region of hyphenated dyad symmetry with the potential for the RNA-like strand to form a hairpin loop. The sequence 432-446 (5'GCCCGAAGCGGGC3'; Fig. 2) is very similar to the Box B element (' ${ }^{\prime}$ GCCCTGAAGAAGGGC3') of the nut $L$ gene of bacteriophage $\lambda$ (Friedman \& Gottesman, 1983). The Box B element tentatively identified in the spacer region (2366-2375) has a different sequence. 


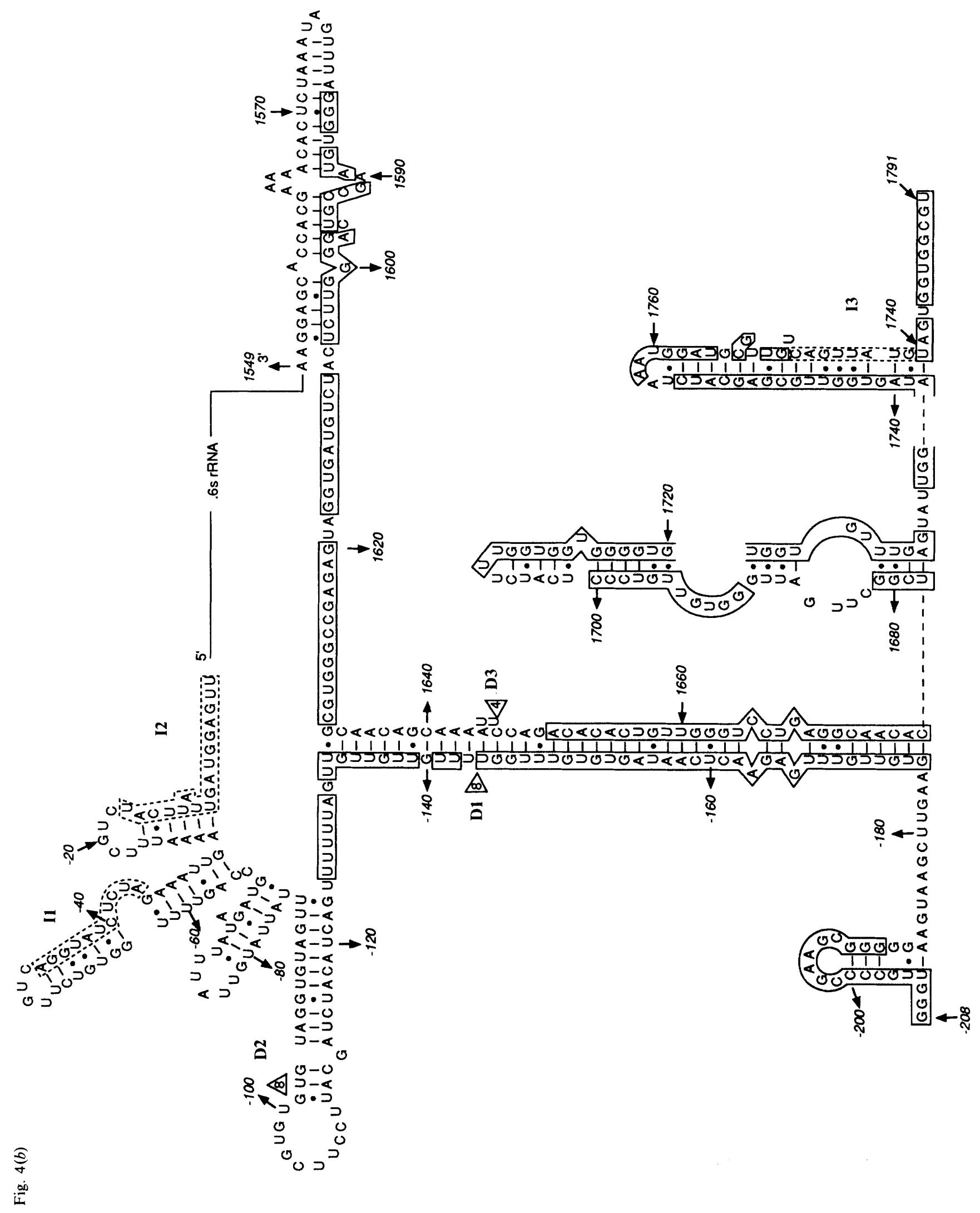


Fig. 4(c)

(i)

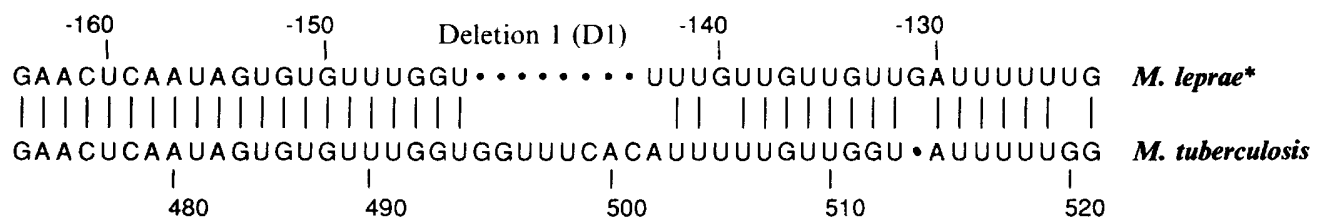

(ii)

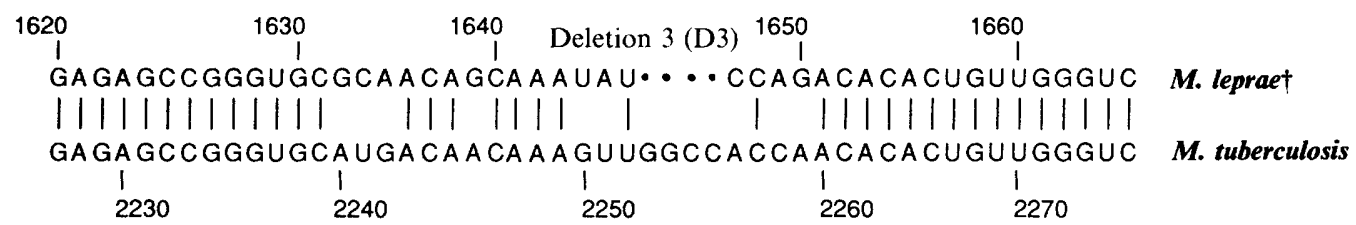

Fig. 4. Scheme for the secondary structure of precursor rRNA of $M$. tuberculosis H37Rv and $M$. leprae. (a) $M$. tuberculosis precursor rRNA. The region of the stem which is similar to B. subtilis pre-rRNA (Ogasawara et al., 1983) is boxed. The arrows indicate possible RNAase III cleavage sites. Box A, Box B and Box C indicate putative antitermination signals (Li et al., 1984). Residues 2287-2390 implicated in the processing of 23S rRNA are framed. $----\rightarrow$ denotes an imperfect 12 bp palindrome; mismatched cytosine residues are marked by an asterisk. Nucleotides are numbered as in Fig. 2. (b) Comparison of the calculated secondary structures of $M$. tuberculosis and $M$. leprae precursor rRNAs. The boxes indicate regions of identical sequence: regions II, I2 and I3, enclosed by a broken line, are sequences not present in $M$. tuberculosis; D1 $\gg, \mathrm{D} 2 \otimes$ and D3 $\gg$ indicate where a number of extra nucleotides (number indicated in the triangle) are present in the $M$. tuberculosis sequence. These sequences specific for $M$. tuberculosis are shown in (c). Nucleotides are numbered from the $5^{\prime}$-end of the $16 \mathrm{~S}$ rRNA coding region. The minus sign denotes upstream sequences. The sequence of the spacer region was reported by Liesack et al. (1991). (c) Comparison of the nucleotide sequences of $M$. tuberculosis and $M$. leprae in (i) the leader, and (ii) the spacer regions of pre-rRNA which are believed to interact through basepairing to form a stem structure, as shown in $(a)$ and $(b) .{ }^{*}$ EMBL Data Library accession number X58891; $\dagger$ Liesack et al. (1991).

The Box A motif has a more conserved sequence which is $5^{\prime}(\mathrm{C} / \mathrm{T}) \mathrm{GCTCTT}(\mathrm{T}) \mathrm{A} 3^{\prime}$ in bacteriophage $\lambda$ (Friedman \& Gottesman, 1983), 5'TGCTCTTTA3' in the $r r n G$ operon of $E$. coli ( $\mathrm{Li}$ et al., 1984) and 5'AGTTCTTTG3' in the $r r n O$ operon of $B$. subtilis (Ogasawara et al., 1983). Homologous sequences are found in positions 463-471 (5'TGTTGTTTG3') and 2398-2406 (5'TGTTCTTTG3') of Fig. 2.

The Box $\mathrm{C}$ element has the consensus sequence $5^{\prime} \mathrm{GG}(\mathrm{T} / \mathrm{C}) \mathrm{GT}(\mathrm{G} / \mathrm{A})(\mathrm{T} / \mathrm{C}) \mathrm{G} 3^{\prime}$ in bacteriophage $\lambda$ (Friedman \& Gottesman, 1983) and 5'TGTGTGGG3' in the rrnG operon of E. coli (Li et al., 1984); the M. tuberculosis homologue appears to be 5'AGTGTGTTT3' (positions 483-498, Fig. 2).

The putative elements described above are in accord with the notion that the leader sequence of pre-rRNA of M. tuberculosis comprises 191 nucleotides, compared with 110-175 nucleotides noted for the leader region of $r r n$ operons of B. subtilis (Ogasawara et al., 1983). A potential secondary structure was derived for the transcript by the method of Staden (1984), including the putative stem structure formed by basepairing between leader and spacer sequences (see Fig. $4 a$ ), described by Young \& Steitz (1978) for E. coli and by Ogasawara et al. (1983) for B. subtilis. The stem region (Fig. $4 a$ ) has $82 \%$ homology with its $B$. subtilis counterpart. The $B$. subtilis sequence (Ogasawara et al., 1983) is 5'GUUCUUUGAAAA $\downarrow C U \downarrow A A A 3^{\prime}$ (the arrows indicate RNAase III cleavage sites) compared with the $M$. tuberculosis sequence 5 'GUUGUUUGAGAA ${ }^{\prime} \mathrm{CU}_{\downarrow} \mathrm{CAA}^{\prime}{ }^{\prime}$ (the broken arrows indicate possible RNAase III cleavage sites). Part of the leader region (positions 464-478) is largely repeated in the spacer region (positions 2396-2416), namely 5'GCGUGUUGUUUGUGCAAUAC3' (see Figs 2 and $4 a$ ). This repeat sequence is a candidate for one strand of a second stem structure (including an RNAase III processing site) formed by interaction with sequences downstream from the $3^{\prime}$-end of 23S rRNA (cf. B. subtilis; Ogasawara et al., 1983). In the $r r n$ operons of B. subtilis (Stewart \& Bott, 1983), Mycoplasma (Taschke \& Herrman, 1986) and Streptomyces (Pernodet et al., 1989), the Box A motif is located within the stem structure close to the RNAase III processing site, as we have found for $M$. tuberculosis (see Fig. $4 a$ ).

The spacer region (Fig. 2) comprises $276 \mathrm{bp}$, which is the same length as the $M$. bovis BCG spacer (Suzuki et $a l ., 1988 a$ ) but which is 6 bp shorter than the $M$. leprae spacer (Liesack et al., 1991). We did not detect tRNA genes in the spacer region (see Fig. 2). In this respect, 
M. tuberculosis resembles $M$. bovis BCG (Suzuki et al., 1988a), M. leprae (Liesack et al., 1991), both operons of Mycoplasma capricolum (Sawada et al., 1984), the single operon of Mycoplasma hyopneumoniae (Taschke \& Herrmann, 1986), Streptomyces ambofaciens (Pernodet et al., 1989), Streptomyces coelicolor (Bayliss \& Bibb, 1988), Streptomyces lividans TK21 (Suzuki et al., 1988b), and eight out of ten of the B. subtilis rrn operons (Loughney $\boldsymbol{e t}$ al., 1982). However, tRNA genes have been located downstream of the $r r n$ operon of $M$. tuberculosis (Bhargava et al., 1990).

\section{$M$. leprae precursor $r R N A$}

The nucleotide sequence of the Sau3A/PstI fragment of the $M$. leprae $r r n$ operon was established and was combined with published data for the spacer region separating the 16S rRNA and 23S rRNA genes (Liesack et al., 1991) to generate a possible secondary structure for the putative precursor rRNA (see Fig. $4 b$ ). Comparison of Figs $4(a)$ and $4(b)$ reveals that the same overall scheme of secondary structure may apply to both $M$. tuberculosis and $M$. leprae, although there are appreciable differences in detail. For example, the putative stringent response and antitermination signals, and RNAase III processing sites are very similar; however, the leader sequence is longer in $M$. leprae (208 nucleotides) than in $M$. tuberculosis (191 nucleotides).

The leader sequence presented in Fig. 4(b) differs from the published sequence (Sela \& Clark-Curtiss, 1991) by the presence of two additional $\mathrm{C}$ residues in the putative Box $B$ antitermination signal forming a run of four consecutive $C$ residues.

The differences in the secondary structure of precursor rRNA of $M$. leprae and $M$. tuberculosis are attributable to insertions and deletions in the $M$. leprae leader and spacer regions compared with $M$. tuberculosis (see Fig. $4 c$ ). The bihelical stem region formed between part of the leader sequence and part of the spacer region provides evidence for compensating changes; for example, deletion D1 [Fig. $4 c$ (i)] in the leader sequence is matched by deletion $\mathrm{D} 3$ in the spacer region [Fig. $4 c$ (ii)]. The high degree of homology (see Fig. $4 b$ ) between the secondary structures proposed for $M$. leprae and $M$. tuberculosis, together with the evidence for compensating changes, lends support to the schemes proposed in Fig. 4.

\section{Discussion}

Members of the $M$. tuberculosis family have a single $r r n$ operon (K. E. Kempsell, I. C. E. Estrada-G, M. J. Colson \& R. A. Cox, unpublished work). They also have fewer ribosomes than many other bacteria. However, their complement of ribosomes varies according to the growth rate (Winder \& Rooney, 1970). More than $80 \%$ of the RNA fraction of a bacterium is rRNA, so that the ribosome complement is reflected in the RNA:DNA ratio. In the mid-exponential phase this ratio is $2: 1$ for M. tuberculosis, 4:1 for Mycobacterium smegmatis and 20:1 for E. coli (Winder \& Rooney, 1970), that is the complement of ribosomes are in the proportions $1: 2: 10$. $M$. tuberculosis has a single $r r n$ operon, $M$. smegmatis has two (Bercovier et al., 1986) and E. coli has seven (Kiss et al., 1977). The single operon of $M$. tuberculosis provides about $70 \%$ of the number of ribosomes synthesized by one operon of $E$. coli, on the basis of the assumption that the seven operons are equivalent. The evidence that $M$. tuberculosis maintains growth-rate-dependent control of ribosome biosynthesis rests on the observation that the RNA : DNA ratio varies according to growth conditions whereas the ratio RNA:protein remains unchanged (Winder \& Rooney, 1970). The sequence data presented above for $\boldsymbol{M}$. tuberculosis has similarities with elements of the promoter and leader regions of the $r r n$ operons of $B$. subtilis and E. coli, suggesting that they have similar mechanisms for the control of rRNA synthesis.

On the basis of its similarity with $M$. tuberculosis precursor rRNA, the single rrn operon of $M$. leprae appears functional (see also Sela \& Clark-Curtiss, 1991). Indeed, the RNA : DNA ratio of $M$. leprae indicates that each cell contains at least 2000 ribosomes (Estrada-G et $a l ., 1988)$. Thus it is unlikely that the exceptionally slow growth rate of $M$. leprae arises from a defect in its capacity for ribosome biosynthesis. A more likely explanation is that, for other reasons, $M$. leprae is incapable of independent growth and survives as an obligate parasite (for review see Wheeler, 1990).

The sequence of the $r r n$ operon of $M$. bovis extending from 100 bp upstream from the start of the 16S rRNA coding region through the spacer region to the start of the 23S rRNA coding region (2007 bp) was reported previously (Suzuki et al., 1988a). There are four differences compared with the equivalent $M$. tuberculosis sequence. The single difference in the 16S rRNA coding region was discussed above; the three other differences are found in the spacer region [positions $2169(\mathrm{G} / \mathrm{C})$, $2170(\mathrm{C} / \mathrm{G})$ and $2261(\mathrm{~A} / \mathrm{C})$ ] as shown in Fig. 2. These four differences in 2007 bp result in $99.8 \%$ similarity in sequence. Members of the $M$. tuberculosis complex are also very closely related $(98 \%$ similarity in $16 \mathrm{~S}$ rRNA sequences) to other slow-growing mycobacteria (Rogall et al., 1990; Stahl \& Urbance, 1990; Cox et al., 1991). This high degree of similarity in sequence suggests that the principal features of the leader region of the $M$. tuberculosis $r r n$ operon are present not only in other members of the $M$. tuberculosis complex but also in other slow-growing mycobacteria. We have presented supporting evidence to show that this inference is true in the case of $M$. leprae. 
This investigation received support from the UNDP/WHO Special Programme for Research Training in Tropical Diseases, and from the British Leprosy Relief Association (LEPRA). Dr Yuan-en $\mathrm{Ji}$ is supported by a grant from LEPRA.

\section{References}

BAYLISS, H. A. \& BIBB, M. J. (1988). Transcriptional analysis of the 16S rRNA gene of the $r r n D$ gene set of Streptomyces coelicolor A3(2). Molecular Microbiology 2, 569-579.

Berg, K. L., SQuires, C. \& SQuires, C. L. (1989). Ribosomal RNA operon anti-termination: function of leader and spacer region Box B-Box A sequences and their conservation in diverse microorganisms. Journal of Molecular Biology 209, 345-358.

BerCovier, H., KAFrI, O. \& Sela, S. (1986). Mycobacteria possess a surprisingly small number of ribosomal RNA genes in relation to the size of their genome. Biochemical and Biophysical Research Communications 136, 1136-1141.

Bhargava, S., Tyagi, A. K. \& Tyagi, J. S. (1990). tRNA genes in mycobacteria: organization and molecular cloning. Journal of Bacteriology 172, 2930-2934.

Cox, R. A., Kempsell, K., Fairclough, L. \& Colston, M. J. (1991). The $16 \mathrm{~S}$ ribosomal RNA of Mycobacterium leprae contains a unique sequence which can be used for identification by the polymerase chain reaction. Journal of Medical Microbiology 35, 284-290.

DALE, J. W. \& PATKI, A. (1990). Mycobacterial gene expression and regulation. In Molecular Biology of the Mycobacteria, pp. 173-198. Edited by J. McFadden. London: Surrey University Press.

Dams, E., Hendriks, L., Van De Peer, Y., Neefs, J. M., Smits, G., Vendenbempt, L. \& De WaCHTER, R. (1988). Compilation of small subunit RNA sequences. Nucleic Acids Research 16, r87-r173.

Duester, G., Elford, R. M. \& Holmes, W. M. (1982). Fusion of the Escherichia coli tRNA ${ }^{\text {Leu }}$ promoter to the galK gene: analysis of sequences necessary for growth-rate-dependent regulation. Cell 30, 855-864.

Estrada-G, I. C. E., Colston, M. J. \& Cox, R. A. (1989). Determination and evolutionary significance of nucleotide sequences near to the $3^{\prime}$-end of $16 \mathrm{~S}$ ribosomal RNA of mycobacteria. FEMS Microbiology Letters 61, 285-290.

Friedman, D. I. \& GotTESMAN, M. (1983). The lytic mode of lambda development. In Lambda II, pp. 21-52. Edited by R. Hendrix, J. Roberts, F. Stahl \& R. Weisberg. Cold Spring Harbor, NY: Cold Spring Harbor Laboratory.

Gourse, R. L., DE BoER, H. A. \& NoMURA, M. (1989). DNA determinants of rRNA synthesis in $E$. coli growth rate dependent regulation, feedback inhibition, upstream activation antitermination. Cell 44, 197-205.

King, T. C., SiRDeskmukh, R. \& SChlessinger, D. (1986). Nucleolytic processing of ribonucleic acid transcripts in procaryotes. Microbiological Reviews 50, 428-451.

Kiss, A., SAin, B. \& Venetianer, P. (1977). The number of rRNA genes in Escherichia coli. FEBS Letters 79, 77-79.

Li, S. C., Squires, C. L. \& SQuires, C. (1984). Antitermination of $E$. coli rRNA transcription is caused by a control region segment containing nut-like sequences. Cell 38, 851-860.

Liesack, W., Pitulle, C., Sela, S. \& Stackebrandt, E. (1990). Nucleotide sequence of the 16S rRNA from Mycobacterium leprae. Nucleic Acids Research 18, 5558.

Liesack, W., Sela, S., Bercovier, H., Pitulle, C. \& Stackebrandt, E. (1991). Complete nucleotide sequence of the Mycobacterium leprae 23S and 5S rRNA genes plus flanking regions and their potential in designing diagnostic oligonucleotide probes. FEBS Letters 281, 114-118.

LOUGHNEY, K., LUND, E. \& DAHLBERG, J. E. (1982). tRNA genes are found between the 16S and 23S rRNA genes in Bacillus subtilis. Nucleic Acids Research 10, 1607-1624.

LOUGHNEY, K., Lund, E. \& DAHLBERG, J. E. (1983). Ribosomal RNA precursors of Bacillus subtilis. Nucleic Acids Research 11, 6709-6721.
Maniatis, T., Fritsch, E. F. \& Sambrook, J. (1982). Molecular Cloning, a Laboratory Manual. Cold Spring Harbor, NY: Cold Spring Harbor Laboratory.

MURPHY, G. \& WARD, E. S. (1989). Sequencing of double-stranded DNA. In Nucleic Acids Sequencing, a Practical Approach, pp. 99-115. Edited by C. J. Howe \& E. S. West. Oxford: IRL Press.

Noller, H. (1984). Structure of ribosomal RNA. Annual Review of Biochemistry 53, 119-231.

Ogasawara, N., Moriya, S. \& Yoshikawa, H. (1983). Structure and organization of rRNA operons in the region of the replication origin of the Bacillus subtilis chromosome. Nucleic Acids Research 11, 6301-6318.

Pernodet, J.-L., Boocard, F., Alegre, M.-T., Gagnat, J. \& GUERINEAU, M. (1989). Organization and nucleotide sequence analysis of a ribosomal RNA cluster from Streptomyces ambofaciens. Gene 59, 33-46.

Rogall, T., Flohr, T. \& Bottger, E. C. (1990). Differentiation of Mycobacterium species by direct sequencing of amplified DNA. Journal of General Microbiology 136, 1915-1920.

SANGER, F., NiCKLEN, S. \& Coulson, A. R. (1977). DNA sequencing with chain-terminating inhibitors. Proceedings of the National Academy of Sciences of the United States of America 74, 54635467.

Sawada, M., Muto, A., Iwami, M., Yamao, F. \& Osawa, S. (1984). Organization of ribosomal RNA genes in Mycoplasma capricolum. Molecular and General Genetics 196, 311-316.

Sela, S. \& Clark-CurTiss, J. E. (1991). Cloning and characterization of the Mycobacterium leprae putative ribosomal RNA promoter in Escherichia coli. Gene 98, 123-127.

SHEPARD, C. C. (1960). The experimental disease that follows the injection of human leprosy bacilli into the footpads of mice. Journal of Experimental Medicine 112, 445-454.

Shine, J. \& Dalgarno, L. (1974). The 3'-terminal sequence of Escherichia coli $16 \mathrm{~S}$ ribosomal RNA: complementarity to nonsense triplets and ribosome binding sites. Proceedings of the National Academy of Sciences of the United States of America 71, 13421346.

STADEN, R. (1984). Computer methods to locate signals in nucleic acid sequences. Nucleic Acids Research 12, 505-519.

Stahl, D. A. \& URBanCE, J. W. (1990). The division between fast- and slow-growing species correspond to natural relationships among the mycobacteria. Journal of Bacteriology 172, 116-124.

Stewart, G. C. \& BotT, K. F. (1983). DNA sequence of the tandem ribosomal RNA promoter for B. subtilis operon $r r n B$. Nucleic Acids Research 11, 6289-6300.

Suzuki, Y., Nagata, A., ONo, Y. \& Yamada, I. (1988a). Complete nucleotide sequence of the 16S rRNA gene of Mycobacterium bovis BCG. Journal of Bacteriology 170, 2886-2889.

Suzuki, Y., Ono, Y., Nagata, A. \& Yamada, T. (1988b). Molecular cloning and characterization of an rRNA operon in Streptomyces lividans TK21. Journal of Bacteriology 170, 1631-1636.

TASCHKe, C. \& HERRMANN, R. (1986). Analysis of transcription and processing signals of the $16 \mathrm{~S}-23 \mathrm{~S}$ rRNA operon of Mycoplasma hyopneumoniae. Molecular and General Genetics 205, 434-441.

WAYNE, L. G. (1982). Microbiology of tubercle bacilli. American Review of Respiratory Diseases 125, 31-41.

WHEELER, P. R. (1990). Recent research into the physiology of Mycobacterium leprae. Advances in Microbial Physiology 31, 70-124.

WINDER, F. G. \& RoONEY, S. A. (1970). Effects of nitrogenous components of the medium on the carbohydrate and nucleic acid content of Mycobacterium tuberculosis BCG. Journal of General Microbiology 63, 29-39.

WINSHIP, P. R. (1989). An improved method for directly sequencing PCR amplified material by using dimethylsulphoxide. Nucleic Acids Research 17, 1266.

Young, R. A. \& Steitz, J. A. (1978). Complementary sequences 1700 nucleotides apart form a ribonuclease III cleavage site in Escherichia coli ribosomal precursor RNA. Proceedings of the National Academy of Sciences of the United States of America 75, 3503-3597. 